\title{
Physical-chemical and electrochemical properties of sodium ion conducting polymer electrolyte using copolymer poly(vinylidene fluoride- hexafluoropropylene) (PVDF-HFP)/ polyethylene oxide (PEO)
}

\author{
Vo Duy Thanh ${ }^{1}, *$, Phung Minh Trung ${ }^{2}$, Truong Quoc Duy Hoang ${ }^{2}$, Le Thi My Linh ${ }^{2}$, Nguyen Hoang Oanh ${ }^{2}$, Le \\ My Loan Phung ${ }^{1,2}$
}

${ }^{1}$ Key laboratory of Applied Physical Chemistry (APCLAB),

VNUHCM-University of Science

${ }^{2}$ Department of Physical Chemistry, Faculty of Chemistry, VNUHCM-

University of Science

\section{Correspondence}

Vo Duy Thanh, Key laboratory of Applied Physical Chemistry (APCLAB),

VNUHCM-University of Science

Email: vodthanh@hcmus.edu.vn

\section{History}

- Received: 05-12-2018

- Accepted: 19-03-2019

- Published: 29-03-2019

DOI :

https://doi.org/10.32508/stdj.v22i1.1230

\section{Check for updates}

\section{Copyright}

(c) VNU-HCM Press. This is an openaccess article distributed under the terms of the Creative Commons Attribution 4.0 International license.

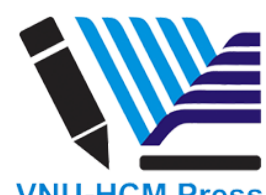

\begin{abstract}
Introduction: Polymers acting as both an electrolyte and a separator are of tremendous interest because of their many virtues, such as no leakage, flexible geometry, excellent safe performance, and good compatibility with electrodes, compared with their liquid counterparts. In this study, polymer electrolyte membranes comprising of poly(vinylidene fluorine-co-hexafluoropropylene) [PVDF-HFP] were plasticized with different mass ratios of poly(ethylene oxide) (PEO) in $1 \mathrm{M}$ $\mathrm{NaClO}_{4} / \mathrm{PC}$ solutions, and were prepared and characterized in sodium-ion battery. Methods: Polymer electrolyte membranes were prepared by solution-casting techniques. The membranes' performance was evaluated in terms of morphology, conductivity, electrochemical stability, thermal properties and miscibility structure. The following various characterization methods were used: Scanning Electron Microscopy (SEM), impedance spectroscopy (for determination of electrolyte resistance), cyclic voltammetry, thermal degradation analysis, and infra-red spectroscopy (for determination of structure of co-polymer). Results: It was indicated that the PVDF-HFP/PEO membrane with $40 \%$ wt. PVDF-HFP absorbed electrolytes up to $300 \%$ of its weight and had a roomtemperature conductivity of $2.75 \times 10^{-3} \mathrm{Scm}^{-1}$, which was better than that of pure PVDF-HFP. All polymer electrolyte films were electrochemically stable in the potential voltage range of $2-4.2 \mathrm{~V}$, which could be compatible with 3-4 V sodium material electrodes in rechargeable sodium cells. Conclusion: The PVDF-HFP/PEO polymer electrolyte film is a potential candidate for sodium-ion battery in the potential range of 2-4.2 V.
\end{abstract}

Key words: Ionic conductivity, Na-ion battery, PEO, Polymer electrolyte, PVDF-HFP

\section{INTRODUCTION}

The widespread deployment of renewable energy demands rapid growth in the production of cheap, efficient energy storage systems. Extending battery technology to large storage will become essential as renewable energy, such as wind, solar and waves, becomes more common and integrated into the grid. While the lithium-ion battery technology is quite mature, there are still questions regarding lithium battery safety, longevity, low temperature resistance and cost. Furthermore, as the use of large-capacity lithium batteries becomes more prevalent, increased demand for lithium chemicals combined with geographically limited lithium resources will increase prices. Based on the wide availability and low cost of sodium resources, the sodium batteries have the potential to meet the needs of large-scale energy storage. In addition, because sodium is plentiful (the $4^{\text {th }}$ most abundant element in the earth's crust), the sodium battery can replace the lithium battery and compete with the lithium battery in many markets. The abundance of resources and lower costs show the potential for using the sodium battery in large-scale applications, especially in the near future ${ }^{1-4}$.

The search for suitable electrolytes and highperformance cathode materials is critical to the battery research requirements. The most common electrolytes for sodium batteries use $\mathrm{NaPF}_{6}$ or $\mathrm{NaClO}_{4}$ as salts in carbonate esters, especially propylene carbonate (PC). An electrolyte for the sodium batteries usually has some of the following characteristics: chemical stability, electrochemical stability, heat stability, high ionic conductivity, low electronic conductivity, high electrode surface permeability, and low toxicity ${ }^{5}$.

Compared to electrolyte liquids and ionic liquids, polymer electrolyte is also considered as a potential candidate for sodium batteries. In addition, it can

Cite this article : Duy Thanh V, Minh Trung P, Quoc Duy Hoang T, Thi My Linh L, Hoang Oanh N, My Loan Phung L. Physical-chemical and electrochemical properties of sodium ion conducting polymer electrolyte using copolymer poly(vinylidene fluoride- hexafluoropropylene) (PVDF-HFP)/ polyethylene oxide (PEO). Sci. Tech. Dev. J.; 22(1):147-157. 
act as an ion-conducting membrane with outstanding features, such as thermal stability and flexibility, easy battery manufacturing, and non-electronical conductivity. Polymer electrolytes are generally divided into two types: solid-state polymer electrolyte (SPE) and gel polymer electrolyte (GPE). In GPE, the polymer matrix provides mechanical support and swelling by absorbing liquid electrolytes to allow ion transport. Solvents for sodium batteries may be organic solvents or ionic liquids. Thus, GPE is an electrolytic membrane consisting of salts and organic solvents contained in the polymer matrix. GPEs generally have lower mechanical strength than SPEs, but at the same time have higher ionic conductivity and better contact with electrode materials. GPE is developed on a variety of polymers, including poly (vinylidene fluoride) (PVDF), poly (methyl methacrylate) (PMMA), and poly (acrylonitrile) (PAN) ${ }^{6,7}$.

In 1994, the Telcordia Institute of Technology (formerly Bellcore) ${ }^{8}$ first reported on poly(vinylidene fluoride-co-hexafluoropropylene) (PVDF-HFP) electrolytic membrane, which showed favorable ionic conductivity at room temperature after soaking with liquid electrolyte. However, due to the presence of fluorine atoms, this electrolytic membrane cannot be used in rechargeable lithium batteries due to chemically compromised interfering problems leading to depletion. To overcome this problem, polymer blending is another useful technique for designing polymer material with attractive properties. L. Sannier and colleagues ${ }^{9}$ used acetone and acetonitrile to synthesize PVDF-HFP/PEO membrane to overcome the limitations of the Bellcore membrane. Furthermore, the addition of PEO not only increased the porosity and uptake for liquid electrolyte, but also increased the ionic conductivity. In our knowledge, there have been few studies focusing on the blended polymer based on PVDF-HFP for sodium-ion batteries.

In this study, we aim to improve the electrochemical performance of PVDF-HFP membrane by using PEO blended into this polymer. The PVDFHFP polymer films were prepared by a solutioncasting technique using acetone and acetonitrile. $1 \mathrm{M}$ $\mathrm{NaClO}_{4} / \mathrm{PC}$ is then used as a plasticizer to form a gel film. Gel membrane after gelatinization was investigated for liquid electrolyte absorption, surface morphology with Scanning Electron Microscopy (SEM), Attenuated Total Reflectance Infrared Spectroscopy (ATR-IR), ionic conductivity with electrochemical impedance spectroscopy (EIS), electrochemical stability with cyclic voltammetry (CV), and heat stability with thermogravimetric analysis (TGA).

\section{METHODS}

\section{Preparation of PVDF-HFP/PEO membrane}

PVDF-HFP $\left(\mathrm{M}_{w}=400,000 \mathrm{~g} / \mathrm{mol}\right)$, PEO $\left(\mathrm{M}_{v}=\right.$ $300,000 \mathrm{~g} / \mathrm{mol}), \mathrm{NaClO}_{4}(99.99 \%)$, and propylene carbonate (PC, 99.99\%) were procured from SigmaAldrich (St. Louis, MO, USA). PVDF-HFP/PEO films with different mass ratios were synthesized by homogenization in the mixture of acetone/acetonitrile solvents. Firstly, PVDF-HFP was gradually dissolved in a solvent mixture $(15 \mathrm{~mL}$ of acetone and $20 \mathrm{~mL}$ of acetonitrile) in a $50 \mathrm{~mL}$ flask. After that, PEO was added and vigorously stirred for 15 minutes. The reaction mixture was then stirred at $50{ }^{\circ} \mathrm{C}$ for 2 hours. The reaction solution was cooled to room temperature and poured into a polytetrafluoroethylene (PTFE) mold to evaporate naturally for 24 hours to form a thin film.

The final samples were abbreviated using the following terms: "[percentage in mass: wt. \%] PVDFHFP/PEO". For example, the sample denoted as " $40 \%$ wt. PVDF-HFP/PEO" was made up of $40 \%$ of PVDFHFP and $60 \%$ of PEO weighted in membrane molding step, without considering other ingredients added later, such as PC solvents or $\mathrm{NaClO}_{4}$ salts, or other elements such as moisture \& the remaining solvent.

\section{Impregnation of PVDF-HFP/PEO mem- branes in $1 \mathrm{M} \mathrm{NaClO}_{4} / \mathrm{PC}$}

PVDF-HFP/PEO film after natural evaporation was cut into a round shape of $10 \mathrm{~mm}$ diameter and vacuum-dried at room temperature for 24 hours before storage in a vacuum chamber (Glovebox, controlled atmosphere). The liquid electrolyte absorption of PVDF-HFP/PEO membrane when soaking in a 500 $\mathrm{mL}$ volume of $1 \mathrm{M} \mathrm{NaClO}_{4} / \mathrm{PC}$ was investigated. The membrane was initially weighed and immersed in liquid electrolyte. After $t$ minutes, the membrane was removed from the solution, dried on the filter paper, and weighed after removing excess liquid on gel-film surface $^{10}$. The electrolyte absorption of the film was measured by the mass method, calculated by the formula:

$$
\text { \%absorption }=\frac{w_{t}-w_{0}}{w_{0}} \times 100
$$

where $\mathrm{w}_{t}$ is the weight measured after $\mathrm{t}$ minutes soaked and $w_{0}$ is the initial weight of the film ${ }^{2}$. The average weight was calculated for three impregnated membranes with the same initial mass. 


\section{Physical-chemical membranes \\ characterization}

Scanning Electron Microscopy (SEM) snapshot was performed using the Hitachi S-4800 with magnification $\times 500, \times 1000$, and $\times 1500$. ATR FT-IR spectra of pure samples and $\mathrm{x} \%$ wt. PVDF-HFP/PEO were recorded by using FT/IR-6600 type A with $45^{\circ}$ angle, $2 \mathrm{~mm} / \mathrm{s}$ scanning speed, and $8 \mathrm{~cm}^{-1}$ resolution.

The thermal properties of pristine membrane and gel polymer membrane were characterized using Thermogravimetric analysis (TGA) with a TGA Q500 V20.10 Build at a scan rate of $10^{\circ} \mathrm{C} . \mathrm{min}^{-1}$ from room temperature up to $600^{\circ} \mathrm{C}$. All samples were measured with stable Nitrogen flow and a temperature-control chamber.

\section{Electrochemical characterization of mem- branes}

The gel film's electrochemical impedance was analyzed by VSP Biologic 3B-5 SPS to calculate ionic conductivity using a Swagelok cell type (SS (stainless steel) / membrane / SS model). The frequency range of $1 \mathrm{MHz}$ to $100 \mathrm{kHz}$ and the temperature range of 298-343 K were applied for impedance measurement. Cyclic voltammetry was performed on the MPG-2 Biologic multichannel device in the 2.0 to $4.2 \mathrm{~V}$ with a scanning rate of $0.1 \mathrm{mVs}^{-1}$. TGA measurements for samples were conducted in Ar gas from room temperature to $700{ }^{\circ} \mathrm{C}$ on the Linseis TA Evolution V2.2.0, with a heating rate of $10 \mathrm{~K} / \mathrm{min}$ Table 1 .

The ionic conductivity at the corresponding temperature $(\sigma)$ of the polymer electrolyte was obtained from the Nyquist graphs using this equation:

$$
\sigma=\frac{d}{A \times R}
$$

where $\mathrm{d}(\mathrm{cm})$ is the membrane's diameter (which was $10 \mathrm{~mm}$ in this study), A is the membrane's surface $\left(\mathrm{cm}^{2}\right)$, and $\mathrm{R}(\Omega)$ is the real resistance obtained from the Nyquist graph ${ }^{9}$. All measurements were repeated three times to ascertain accuracy.

\section{RESULTS}

\section{Morphology of PVDF-HFP/PEO electrolyte membrane}

Figure 1(a), (b), (c) show the SEM images of the PVDF-HFP/PEO membranes before electrolyte absorption. In general, the membrane was highly homogenous. There was evidently no phase separation or phase cross-section between the two polymer components. Moreover, the membrane had a sponge-like foam structure, uniform pore distribution, and large size (micron size). In comparing to the PVDF-HFP without PEO blends, the surface morphology of the PVDF-HFP/PEO membrane was not smooth and the distribution of the pores was random. By reducing the PEO content in the sample (increasing the PVDF-HFP content), the surface morphology of PVDF-HFP/PEO tended to be smoother and the porous holes tended to be arranged in order (Figure 1b,e). The structure and porosity of the membrane was significantly dependent on the nature and the mass of polymer component ${ }^{[11]}$. When the films absorbed liquid electrolyte, the SEM images showed that the morphology and porosity of the membrane was almost unchanged (Figure 1e,f,g). The size of the porous holes before and after immersion seemed similar; the pore size was about 200 to $10 \mu \mathrm{m}$, and the connection between the pores was good.

\section{Structure compatibility of polymer mem- brane via infrared spectroscopy (ATR-IR)}

IR spectroscopy is an effective way to describe molecular interactions and chemical bonding in polymeric electrolytes.

Figure 2 illustrates the IR spectra in the wave number from 500 to $4000 \mathrm{~cm}^{-1}$ of all PVDF-HFP/PEO blending films with different mass percentages. For blended polymer membranes, peaks at 611 and 761 $\mathrm{cm}^{-1}$ related to the crystalline phase of PVDF-HFP were nearly lost when mixing PEO into the PVDFHFP, and the peak at $873 \mathrm{~cm}^{-1}$ related to the amorphous phase of PVDF-HFP was almost unchanged (only shifted to $877 \mathrm{~cm}^{-1}$ ). Peaks at 1174 and 1400 $\mathrm{cm}^{-1}$ observed for PVDF-HFP were due to the symmetrical stretching of the $-\mathrm{CF}_{2}$ and $-\mathrm{CH}_{2}$ groups and slightly changed in the blended sample (1174 and $1402 \mathrm{~cm}^{-1}$, respectively). The frequencies at 841 and $956 \mathrm{~cm}^{-1}$ belong to the $\mathrm{CH}_{2}$ bending vibrations of the methylene groups and the spiral structure group of the PEO. Oscillations at 1093 and $1146 \mathrm{~cm}^{-1}$ were assigned to the 1095 and $1145 \mathrm{~cm}^{-1} \mathrm{C}-\mathrm{O}-\mathrm{C}$ (symmetric and asymmetric) oscillation of the $\mathrm{PEO}$. The peak observed at $1238 \mathrm{~cm}^{-1}$ was from PEO's C-O variation and shifted to $1234 \mathrm{~cm}^{-1}$ in blended samples. The two bands at 1358 and $1342 \mathrm{~cm}^{-1}$ were $\mathrm{C}-\mathrm{O}-\mathrm{H}$ deformational (in-plane) bands. The $3494 \mathrm{~cm}^{-1}$ pick-up band was the O-H pull-off oscillator in the PEO end-point, which was assigned to the PEO FT-IR spectrum $\left(\mathrm{M}_{w}\right.$ $=300,000$, Sigma Aldrich). The absorption band at $2883 \mathrm{~cm}^{-1}$ in the blended samples was of symmetric and asymmetric C-H symmetry in both PVDF-HFP and $\mathrm{PEO}$ chains ${ }^{11-13}$. 
Table 1: IR absorption bands for polymers and blend polymers obtained from IR spectra indicated in Figure 2

\begin{tabular}{|c|c|c|}
\hline Sample & Wave number $v(\mathrm{~cm}-1)$ & IR absorption \\
\hline \multirow[t]{10}{*}{ PVDF-HFP } & $3046,3000,2923,2854$ & $\mathrm{C}-\mathrm{H}$ stretching symmetric and asymmetric \\
\hline & 1400 & C-F stretching \\
\hline & 1174 & CF2 stretching \\
\hline & 1064 & C-C stretching \\
\hline & 975 & phase $\alpha$ \\
\hline & 873 & Amorphous phase \\
\hline & 835 & phase $\beta$ \\
\hline & 796 & CF3 stretching \\
\hline & 761 & Crystalline phase \\
\hline & 611 & Crystalline phase \\
\hline \multirow[t]{12}{*}{ PEO } & 3494 & $\mathrm{O}-\mathrm{H}$ stretching \\
\hline & $2879,2740,2696$ & $\mathrm{C}-\mathrm{H}$ stretching symmetric and asymmetric \\
\hline & 1465 & $\mathrm{CH} 2$ Scissoring (reversely bending in the plane) \\
\hline & 1358 & $\mathrm{CH} 2$ fluctuating shake in the opposite direction of the plane \\
\hline & 1342 & $\mathrm{CH} 2$ Shake vibration in the same direction outside the plane \\
\hline & 1278 & $\mathrm{C}-\mathrm{O}$ band \\
\hline & 1238 & C-O band \\
\hline & 1146 & $\mathrm{C}-\mathrm{O}-\mathrm{C}$ band \\
\hline & 1093 & $\mathrm{C}-\mathrm{O}-\mathrm{C}$ band \\
\hline & 1058 & C-O-C stretching \\
\hline & 956 & $\mathrm{C}-\mathrm{H}$ stretching bending in the same plane and partly $\mathrm{C}-\mathrm{O}$ stretching \\
\hline & 841 & $\mathrm{C}-\mathrm{O}$ stretching and partly $\mathrm{C}-\mathrm{H}$ bending in the same plane \\
\hline \multirow{13}{*}{$\begin{array}{l}\text { PVDF-HFP } \\
\text { blended PEO }\end{array}$} & 3494 & $\mathrm{O}-\mathrm{H}$ stretching \\
\hline & 2883 & $\mathrm{C}-\mathrm{H}$ stretching symmetric and asymmetric \\
\hline & 1465 & $\mathrm{CH} 2$ scissoring (reversely bending in the plane) \\
\hline & 1403 & C-F stretching \\
\hline & 1342 & $\mathrm{CH} 2$ Shake vibration in the same direction outside the plane \\
\hline & 1278 & C-O band \\
\hline & 1234 & C-O band \\
\hline & 1174 & CF2 stretching \\
\hline & 1145 & $\mathrm{C}-\mathrm{O}-\mathrm{C}$ band \\
\hline & 1097 & $\mathrm{C}-\mathrm{O}-\mathrm{C}$ band \\
\hline & 958 & $\mathrm{C}-\mathrm{H}$ stretching bending in the same plane and partly $\mathrm{C}-\mathrm{O}$ stretching \\
\hline & 877 & Amorphous phase \\
\hline & 838 & $\mathrm{C}-\mathrm{O}$ stretching and partly C-H bending in the same plane \\
\hline
\end{tabular}




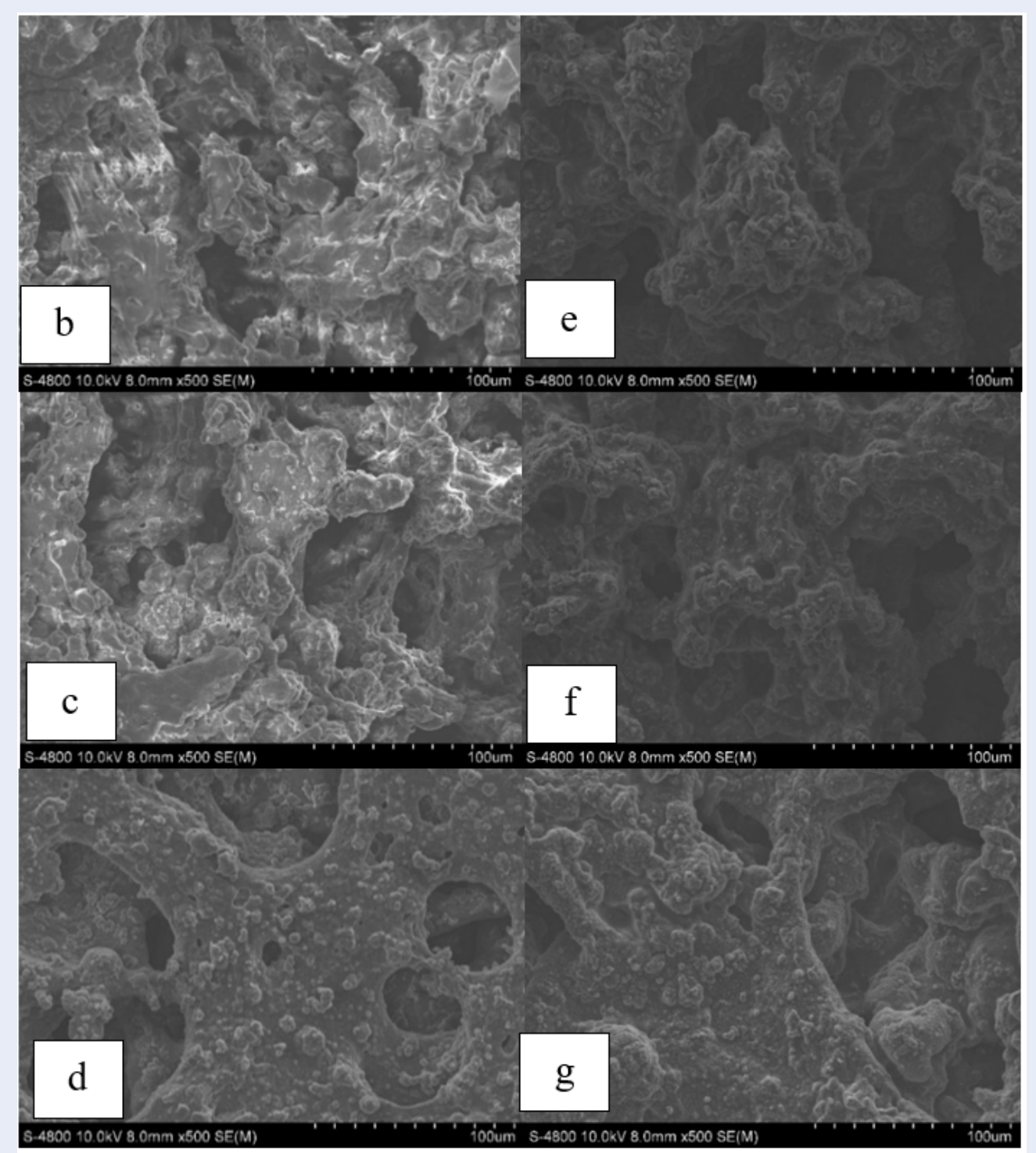

Figure 1: SEM images of $x$ wt. \% P(VDF-HFP) / PEO membranes before and after soaking in the liquid electrolyte solution $\mathbf{N a C l O}_{4} / \mathrm{PC} \mathbf{1} \mathbf{~ M}$, magnification $\times \mathbf{5 0 0}$ (a) 100wt. \% PVDF-HFP before soaking
(b) 40wt. \% PVDF-HFP/PEO before soaking,
(c) 50wt. \% PVDF-HFP/PEO before soaking,
(d) $60 \mathrm{wt} . \%$ PVDF-HFP/PEO before soaking,
(e) 40 wt. \% PVDF-HFP/PEO after soaking,
(f) $50 \mathrm{wt} . \%$ PVDF-HFP/PEO after soaking,
(g) 60wt. \% PVDF-HFP/PEO after soaking. 


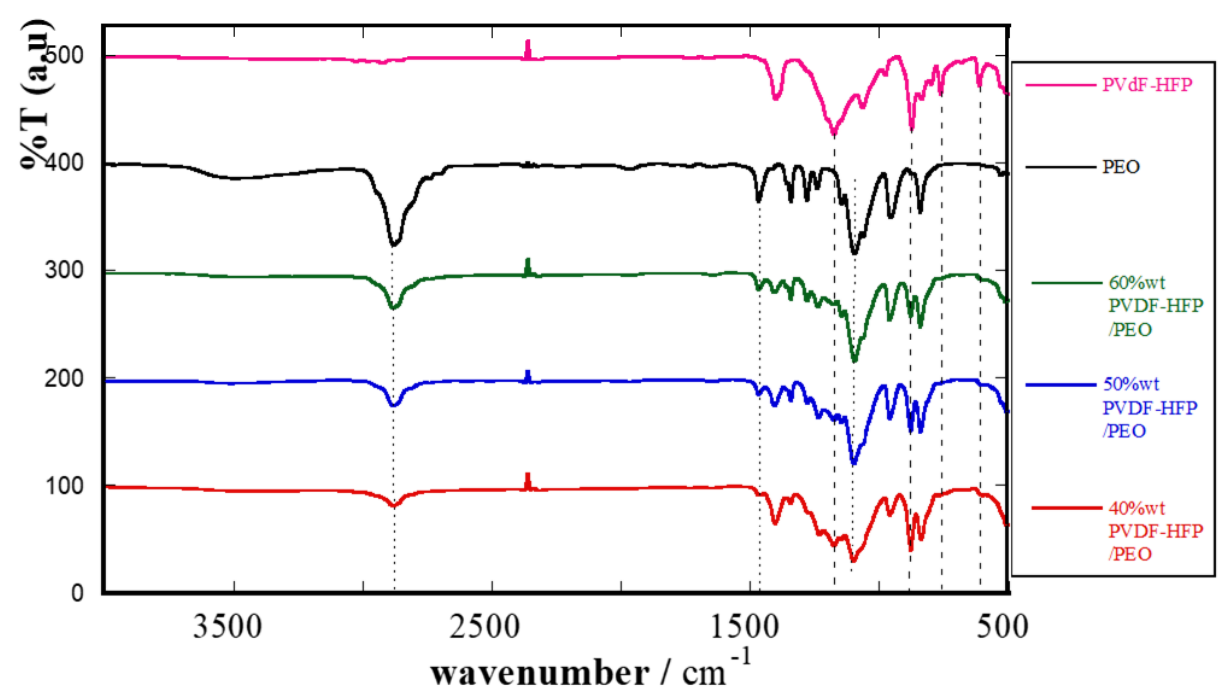

Figure 2: ATR-IR spectra of the $x$ wt. \% PVDF-HFP / PEO and PEO, PVDF-HFP membrane films prior to impregnation in solution of $\mathrm{NaClO} 4$ / PC 1 M.

\section{Electrolyte uptake of gel polymer mem- branes}

The liquid electrolyte absorption diagram of polymer films demonstrated the mass of the membrane when the liquid electrolyte was gradually absorbed over time. In Figure 3, it was found that the liquid electrolyte absorption increased rapidly and reached a saturation at 30 minutes as shown in Table 2. When blending PEO into PVDF-HFP, the permeation time to the liquid electrolyte saturation was faster (pure PVDF-HFP film reached saturation after at least 60 minutes). In addition, when the PEO mixture was mixed, the electrolyte uptake increased dramatically, with an optimum absorption of more than $200 \%$ wt. of that of the original membrane (compared to pure PVDF-HFP carrying alone about $120 \%$ wt.). For different PEO mass ratios, the liquid electrolyte absorption and saturation time will vary due to changes in phase structure, porosity and pore size Figure 4 .

\section{Ionic conductivity of polymer electrolyte membranes}

Ionic conductivity is an important characteristic for GPE applications in rechargeable batteries. The objective of blending PEO into PVDF-HFP to increase the ion conductivity of the film was evaluated by ionic conductivity measurement using the EIS method.

The EIS curve of the SS/GPE/SS (SS:stainless steel) models at $25^{\circ} \mathrm{C}$ to $70^{\circ} \mathrm{C}$ is shown in Figure 5. The extraction of the curve with the real axis (Real $\mathrm{Z}$ axis) in the high frequency band resulted in the resistance of $\mathrm{GPE}$ electrolyte $\mathrm{R}_{b}$. It can be seen from Figure 5 that the $\mathrm{R}_{b}$ value of the $40 \%$ wt. PVDF-HFP/PEO film was $11.95 \Omega$ at $25^{\circ} \mathrm{C}$, while the value at the same temperature of the $60 \%$ wt. PVDF-HFP/PEO film was only at $8.16 \Omega . \sigma_{A c}$ conductivity of the GPE, as calculated by equation (2) (Equation (2)). The increase of ionic conductivity may be due to an increase in the amorphous phase with increasing POE amount.

The ionic conductivity values of PVDF-HFP/PEO membranes in the range of $25^{\circ} \mathrm{C}$ to $70^{\circ} \mathrm{C}$ are shown in Figure 5, and compared with the pure PVDF-HFP membrane (Table 3 ). The increase in ionic conductivity correlating with rising temperature was explained by the flexibility of the polymer chains under thermal impact; the movement of the polymer segment created free space for ions to easily diffuse in the polymer structure.

\section{Electrochemical stability}

Potential window of electrolyte is a crucial factor of the battery to avoid the side effects of electrolyte and electrode material. The redox potential of the film was evaluated by Cyclic Voltammetry (CV) method. CV curves of $\mathrm{x} \%$ wt. PVDF-HFP/PEO membranes containing $1 \mathrm{M} \mathrm{NaClO}_{4} / \mathrm{PC}$, in region 2.0-4.0 $\mathrm{V}$, show the absence of redox peaks, indicating the electrochemical stability of the polymer membrane in this potential range (Figure 6). The oxidation resistance was 


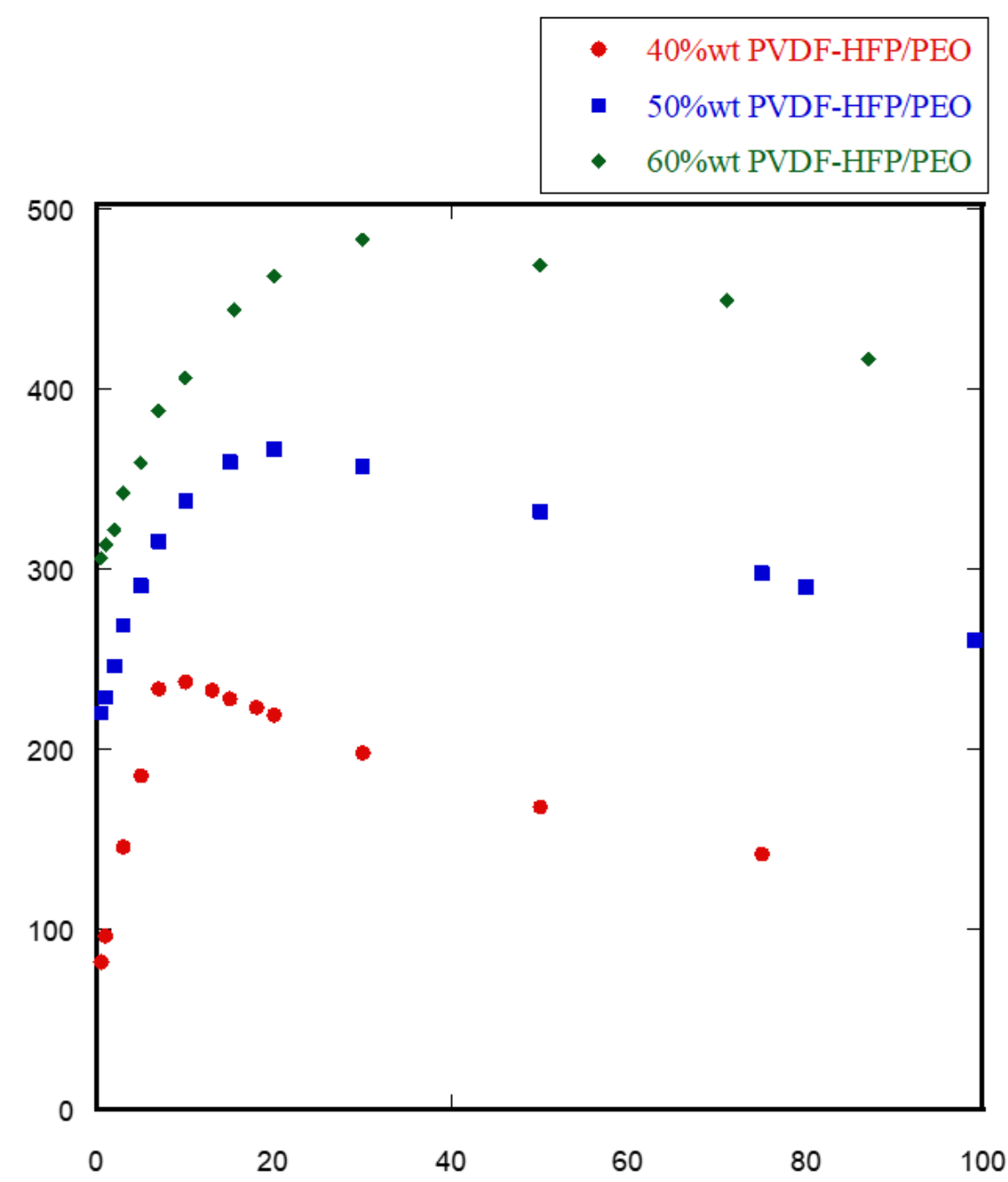

Figure 3: $\mathrm{NaClO}_{4} / \mathrm{PC} 1 \mathrm{M}$ liquid electrolyte absorption of $\mathrm{x}$ wt. \% PVDF-HFP/PEO over time.

Table 2: Maximum absorption of $x$ wt. \% PVDF-HFP / PEO

\begin{tabular}{lll}
\hline Sample & Maximum absorption (wt. \%) & Optimum immersion time (min) \\
40 wt. \% PVDF-HFP/PEO & 237.53 & 10 \\
50 wt. \% PVDF-HFP/PEO & 459.66 & 15 \\
60 wt. \% PVDF-HFP/PEO & 482.75 & 30 \\
\hline
\end{tabular}



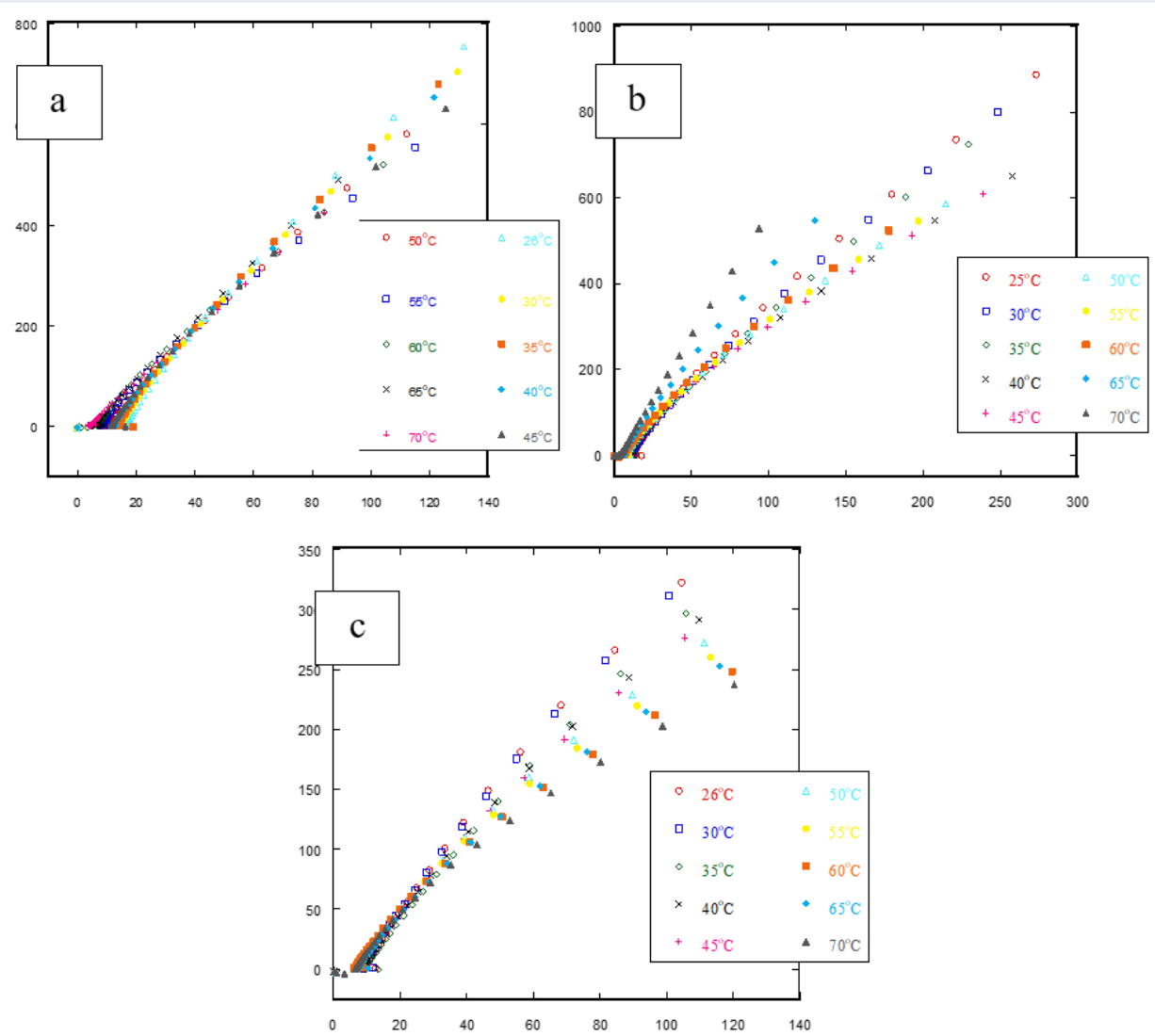

Figure 4: AC EIS spectra of the $x$ wt. \% PVDF-HFP / PEO films after impregnationin $\mathrm{NaClO}_{4}$ / PC 1 M, assembled in Swaglog $(\varphi=10 \mathrm{~mm})$ shells, according to $S S$ / membrane / SS model, in the frequency range from 1 $\mathrm{MHz}$ to $100 \mathrm{kHz}$ at temperatures from $25^{\circ} \mathrm{C}$ to $70^{\circ} \mathrm{C}$. (a) $40 \mathrm{wt}$. \% PVDF-HFP / PEO,

(b) 50 wt. \% PVDF-HFP / PEO,

(c) 60 wt. \% PVDF-HFP / PEO.

Table 3: Ionic conductivity of $x$ wt. \% PVDF-HFP blends PEO compared with PVDF-HFP after impregnation in $\mathrm{NaClO}_{4} / \mathrm{PC} 1 \mathrm{M}$ at $30^{\circ} \mathrm{C}, 50^{\circ} \mathrm{C}, 70^{\circ} \mathrm{C}$

\begin{tabular}{|c|c|c|c|}
\hline $\begin{array}{l}\text { x wt. \% PVDF-HFP / } \\
\text { PEO membranes }\end{array}$ & $\begin{array}{l}\text { Specific conductivity } \sigma \\
\left(\mathrm{mS} . \mathrm{cm}^{-1}\right) \text { at } 30^{\circ} \mathrm{C}\end{array}$ & $\begin{array}{l}\text { Specific conductivity } \sigma \\
\left(\mathrm{mS} . \mathrm{cm}^{-1}\right) \text { at } 50^{\circ} \mathrm{C}\end{array}$ & $\begin{array}{l}\text { Specific conductivity } \sigma \\
\left.(\mathbf{m S . c m})^{-1}\right) \text { at } 70^{o} \mathrm{C}\end{array}$ \\
\hline $40 \%$ & 1.73 & 3.19 & 5.52 \\
\hline $50 \%$ & 2.42 & 4.32 & 7.55 \\
\hline $60 \%$ & 2.75 & 4.38 & 7.09 \\
\hline $100 \%$ & 0.574 & 1.608 & 2.836 \\
\hline
\end{tabular}




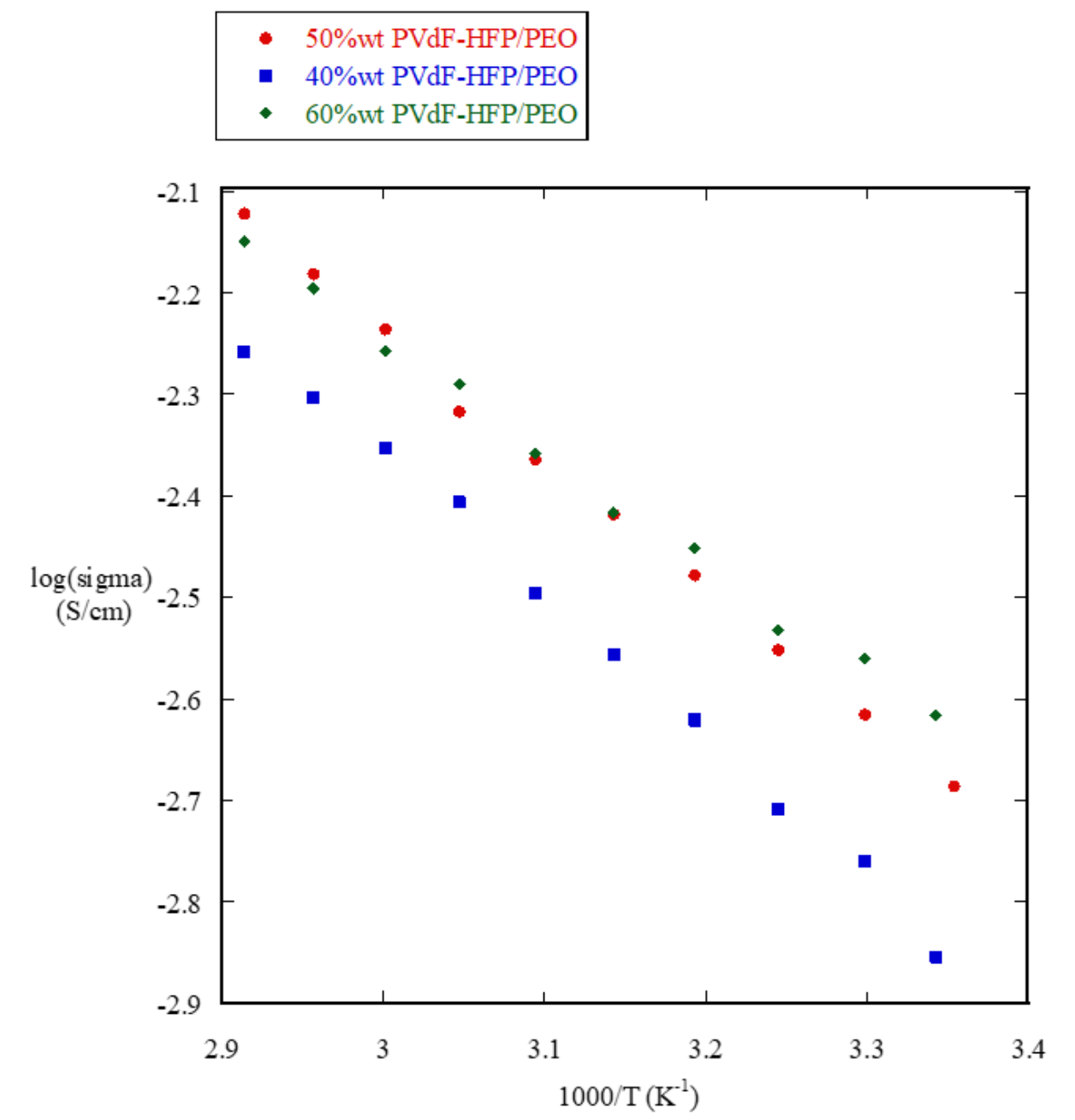

Figure 5: $\log \sigma$ (conductivity) versus $1000 / T$ describing the influence of temperature on conductivity in the range from 298 to $343 \mathrm{~K}$.

achieved at maximum of $3.8 \mathrm{~V}$ vs. $\mathrm{Na}^{+} / \mathrm{Na}$. When increasing the content of PVDF-HFP component in the membrane, the sustainable oxidation current was widened to $4 \mathrm{~V}$ vs. $\mathrm{Na}^{+} / \mathrm{Na}$. This was explained by the higher oxidation resistance of C-F bonding (PVDFHFP structure) (Table 3). Maximum working voltage $\left(\mathrm{V}_{\max }\right)$ could be extended to $4.2 \mathrm{~V}$ with $40 \%$ wt. PVDF-HFP/PEO sample.

\section{Thermal stability analysis (TGA)}

Figure 7 displays the TGA curves of pure PVDF-HFP, pure PEO and $x \%$ wt. PVDF-HFP/PEO films. It can be observed that pure PVDF-HFP has higher thermal stability than pure PEO and blended membrane. Polymer films (x \% wt. PVDF-HFP/PEO) showed two starting points for real weight loss at $310^{\circ} \mathrm{C}$ and $415^{\circ} \mathrm{C}$, corresponding to two thermal decomposition processes of PVDF-HFP and PEO. Degradation temperature of $\mathrm{x} \%$ wt. PVDF-HFP/PEO film is greater than $300^{\circ} \mathrm{C}$, which can meet the thermal safety requirements of rechargeable cells.

\section{DISCUSSION}

As aforementioned, the addition of PEO could obviously improve the pore configuration, such as pore size, porosity, and pore connectivity of PVDF-based microporous membranes. This can be explained by the low crystallinity of PEO with a content of 50$60 \%$ wt., which raises the "amorphous" structure of PVDF-HFP leading to a rough membrane surface with high porosity. Therefore, liquid electrolyte absorption could be increased (Figure 1c,d,f,g). The 


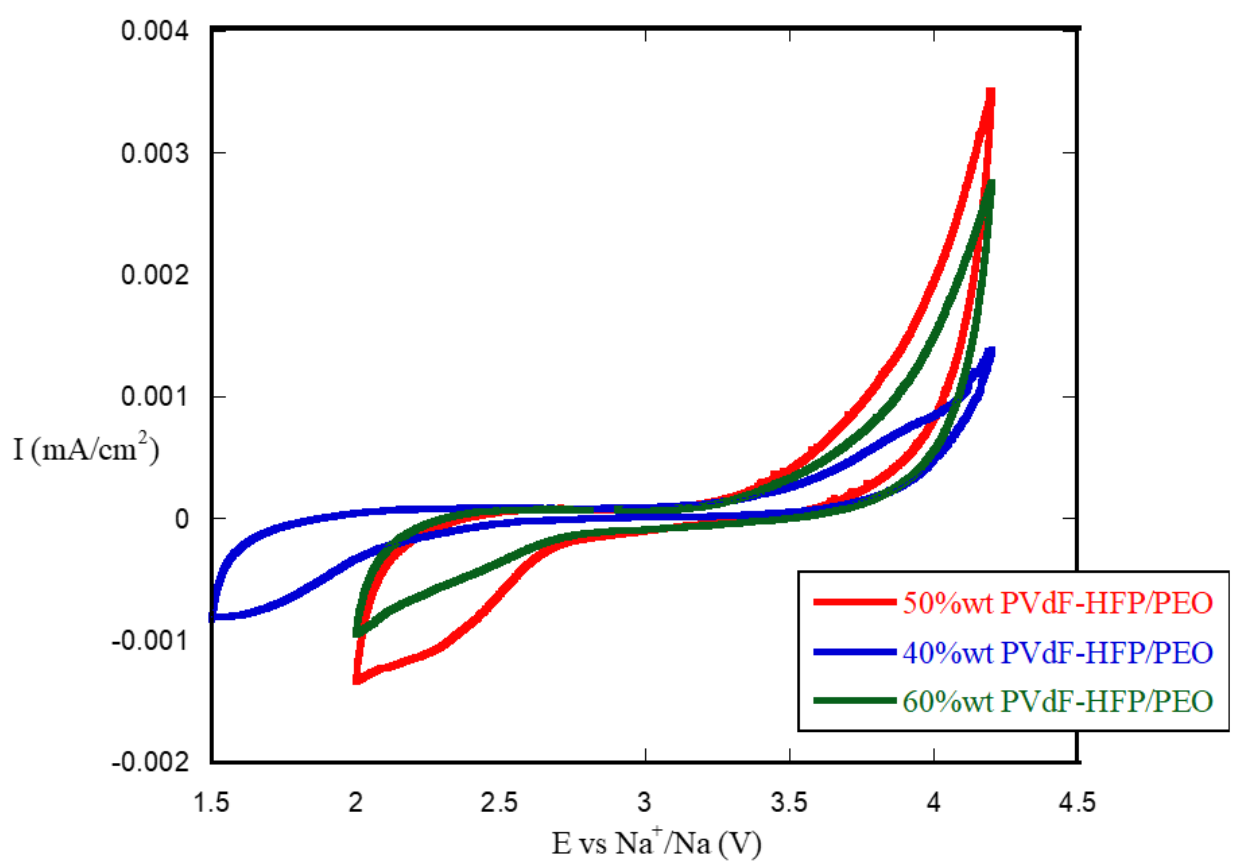

Figure 6: CV curve of the $\mathrm{x}$ wt. \% membraned PVDF-HFP/PEO after impregnation in $\mathrm{NaClO}_{4} / \mathrm{PC} 1 \mathrm{M}$ assembled in Swagelok-cell model: SS model / SS / stainless steel, scanrate $0.1 \mathrm{mVs}^{-1}$ at room temperature.

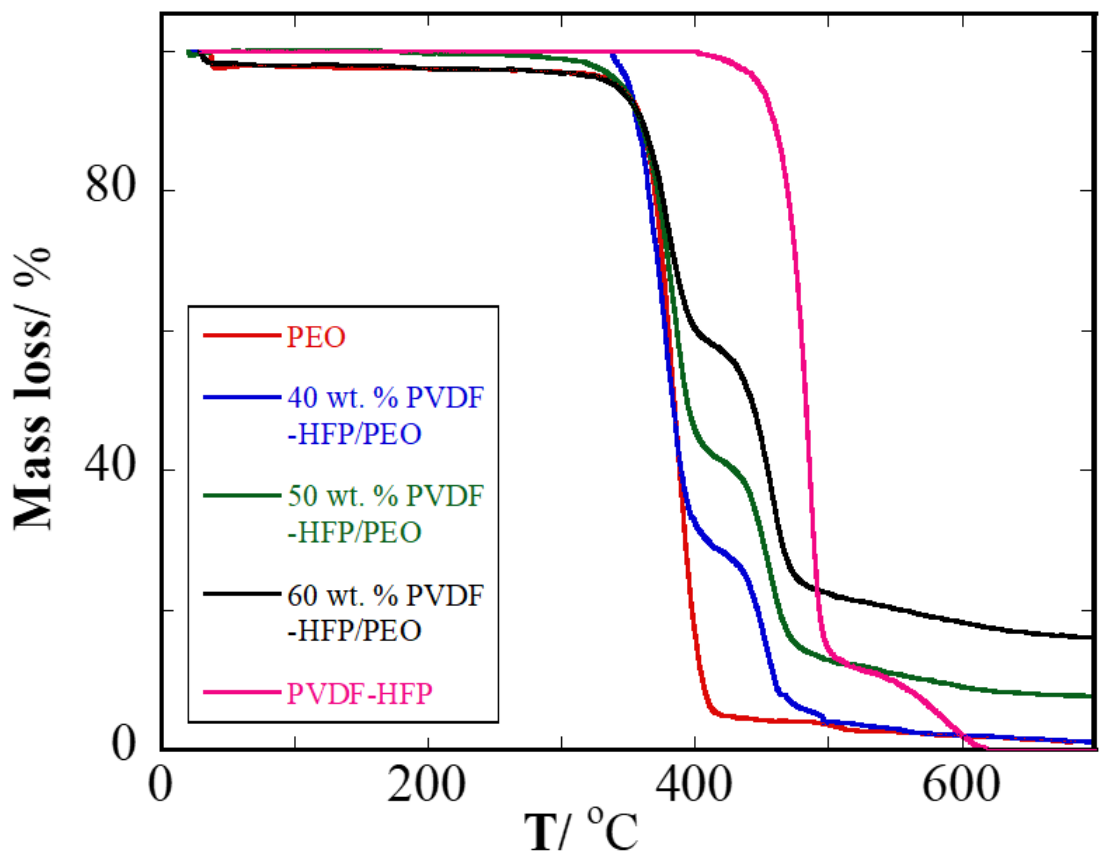

Figure 7: TGA curves of the $x$ wt. \% PVDF-HFP/PEO samples (before impregnation inNaClO $\mathrm{N}_{4} / \mathrm{PC} 1 \mathrm{M}$ ) and pure PEO, pure PVDF-HFP at a temperature from $37^{\circ} \mathrm{C}$ (room temperature) to $700^{\circ} \mathrm{C}$. 
room temperature ionic conductivity was greatly enhanced; ionic conductivity of $60 \%$ wt. PVDF$\mathrm{HFP} / \mathrm{PEO}$ GPE was $2.4 \mathrm{mS} . \mathrm{cm}^{-1}$ at $25^{\circ} \mathrm{C}$ typically. The incorporation of PEO into PVDF-HFP significantly enhances ionic conductivity, which was explained by two reasons: (i) an increase in electrolyte absorption (due to increased porosity and amorphous structure of the membrane); (ii) flexibility of PEO circuit segments and conducting mechanism based on good "solvate" ability of the sodium ion with $\mathrm{OCH}_{2}$ groups ("hopping" mechanism; reduction of interaction between $\mathrm{Na}^{+}$and $\mathrm{ClO}_{4}{ }^{-}$ions) which increase the mobility of sodium ions in favor of soaring ionic conductivity ${ }^{10,14}$.

Additionally, as seen in the IR spectra, PEO blended PVDF-HFP did not have any change in the functional groups of PEO and PVDF-HFP in the blended membrane, indicating that blended polymers do not have any formation of chemical bonding and that PEO decreased principally the crystallinity of the PVDF$\mathrm{HFP} / \mathrm{PEO}$ samples. Indeed, the TGA curve of the PEO blended PVDF-HFP showed two weight loss steps related to the PEO and PVDF initial state. The electrochemical stability of PVDF-HFP/PEO membranes is quite large enough for most of electrode materials (positive and negative) used for sodium-ion batteries.

\section{CONCLUSIONS}

PVDF-HFP/PEO electrolyte membrane has been successfully prepared and investigated for thermal stability, physicochemical and electrochemical properties for application in sodium polymer battery. Blending PEO with PVDF-HFP polymer at appropriate rates can increase the amorphous phase of the polymer structure and increase the electrolyte uptake of blended PVDF-HFP/PEO membranes compared to pure PVDF-HFP film. Ionic conductivity of $60 \%$ wt. PVDF-HFP/PEO GPE is $2.4 \mathrm{mS} . \mathrm{cm}^{-1}$ at $25^{\circ} \mathrm{C}$, which is larger than the GPE of $100 \%$ wt. PVDFHFP. Thus, PVDF-HFP/PEO shows high thermal stability and good electrochemical stability in electricity substrate at 2.0-4.0 V. This implies that the PVDFHFP-PEO blend can be used as a candidate electrolyte and/or separator material for polymer rechargeable batteries.

\section{COMPETING INTERESTS}

The authors declare that there is no conflict of interest regarding the publication of this article.

\section{AUTHORS' CONTRIBUTIONS}

All the authors contribute equally to the paper including the research idea, experimental section and written manuscript.

\section{ACKNOWLEDGMENTS}

This research was funded by Vietnam National University - Ho Chi Minh City (VNU-HCM) through research grant number NV2019-19-01.

\section{REFERENCES}

1. Pan H, Hu YS, Chen L. Room-temperature stationary sodiumion batteries for large-scale electric energy storage. Energy Environ Sci. 2013;6(8):2338-60. Available from: 10.1039/ c3ee40847g.

2. Palomares V, Serras P, Villaluenga I, Hueso KB, CarreteroGonzález J, Rojo T. Na-ion batteries, recent advances and present challenges to become low cost energy storage systems. Energy Environ Sci. 2012;5(3):5884-901. Available from: 10.1039/c2ee02781j.

3. Ponrouch $A$, Dedryvère $R$, Monti $D$, Demet $A E, M b a ~ J M$, Croguennec $L$, et al. Towards high energy density sodium ion batteries through electrolyte optimization. Energy Environ Sci. 2013;6(8):2361-9. Available from: 10.1039/c3ee41379a.

4. Linden D, Reddy TB. Handbook of Batteries. 3rd ed. and others, editor. New York: McGraw-hill; 2002.

5. Vignarooban $K$, Kushugra R, Elango A, Badami $P$, Mellander $\mathrm{BE}, \mathrm{Xu} X$, et al. Current trends and future challenges of electrolytes for sodium-ion batteries. Int J Hydrogen Energy. 2016;41(4):2829-46. Available from: 10.1016/j.ijhydene.2015. 12.090 .

6. Kim JK, Lim YJ, Kim H, Cho GB, Kim Y. A hybrid solid electrolyte for flexible solid-state sodium batteries. Energy Environ Sci. 2015;8(12):3589-96. Available from: 10.1039/C5EE01941A.

7. Agrawal RC, Pandey GP. Solid polymer electrolytes: Materials designing and all-solid-state battery applications: an overview. J Phys D Appl Phys. 2008;41(22):223001. Available from: 10.1088/0022-3727/41/22/223001.

8. Tarascon JM, Gozdz AS, Schmutz C, Shokoohi F, Warren PC. Performance of Bellcore's plastic rechargeable Li-ion batteries. Solid State lon. 1996;86:49-54. Available from: 10.1016/01672738(96)00330-X.

9. Sannier L, Bouchet R, Santinacci L, Grugeon S, Tarascon JM. Lithium Metal Batteries Operating at Room Temperature Based on Different PEO-PVdF Separator Configurations. J Electrochem Soc. 2004;151(6):873. Available from: 10.1149/ 1.1710516.

10. Das S, Ghosh A. Charge Carrier Relaxation in Different Plasticized PEO/PVDF-HFP Blend Solid Polymer Electrolytes. J Phys Chem B. 2017;121(21):5422-32. 28489405. Available from: 10.1021/acs.jpcb.7b02277.

11. Vo DT, Nguyen TT, Nguyen TT, Do HN, Tran VM, Le ML. Structure and electrochemical properties of electrochemical performance of sodium ion conducting polymer electrolyte using poly(vinylidene fluoride hexafluoropropylene). In: The 6th Asian Symposium on Advanced Materials; 2017. p. 285-92.

12. Das $S$, Ghosh A. Charge carrier relaxation in different plasticized PEO/PVDF-HFP blend solid polymer electrolytes. J Phys Chem B. 2017;121(21):5422-32. 28489405. Available from: 10.1021/acs.jpcb.7b02277.

13. Zhu Y, Wang F, Liu L, Xiao S, Chang Z, Wu Y. Composite of nonwoven fabric with poly(vinylidene fluoride) as a gel membrane of high safety for lithium ion battery. Energy Environ Sci. 2013;6(2):614-28. Available from: 10.1039/C2EE23564A.

14. Shi J, Yang Y, Shao H. Co-polymerization and blending based PEO/PMMA/P(VDF-HFP) gel polymer electrolyte for rechargeable lithium metal batteries. J Membr Sci. 2018;547:1-10. Available from: 10.1016/j.memsci.2017.10.033. 